\title{
Niños y “mala vida.” Prostitución infantil, criminalización y endocrinología en Buenos Aires entre 1914 y 1934
}

\author{
Mariana Dovio*
}

\begin{abstract}
Resumen
El objetivo de este trabajo es analizar la construcción de la noción de la "mala vida" en relación a la niñez en Buenos Aires entre 1914 y 1934. Por "mala vida" entendemos aquellos comportamientos ligados a la delincuencia y el alcoholismo. En particular, a ciertas actividades marginales que se vincularon a los niños como prostitución y pequeños robos en espacios urbanos. Tendremos en cuenta la producción de historias clínicas que aparecieron desde el Depósito de Contraventores de la Policía de la ciudad de Buenos Aires. Así como, la noción de la peligrosidad infantil desde el punto de vista de la endocrinología y los estudios de biotipología iniciados por Nicolás Pende, de gran influencia en Argentina. Los discursos que estudiaremos aparecieron en la Revista de Criminología, Psiquiatría y Medicina Legal que fue representativa del positivismo criminológico en Argentina.
\end{abstract}

Palabras claves: Niños; "Mala vida”; Prostitución; Endocrinología.

En las primeras décadas del siglo XX aparecieron en la ciudad de Buenos Aires preocupaciones desde ámbitos estatales y académicos por el aumento de la criminalidad entre los sectores más jóvenes de la población. Los niños aparecieron como la matriz del adulto normal y laborioso, de allí surgió el desafió por controlar y educar a la niñez que parecía desviarse de esta senda hacia la "vida del delito". Esto fue parte de una agenda de problemáticas sociales más amplia relativas a la "cuestión social”, que había surgido desde fines del siglo XIX, en torno de la incorporación del país a un régimen de producción capitalista como exportador de materia prima (de trigo, maíz y carnes, entre otros). La "cuestión social" involucró problemas como la falta de vivienda y saturación de los servicios públicos para los contingentes de inmigrantes que llegaban a la ciudad, así como el alcoholismo, prostitución, etc. Ellas fueron expresiones de la distancia entre

\footnotetext{
* Abogada, Magíster en Sociología y Ciencia Política por Facultad Latinoamericana de Ciencias Sociales. Doctoranda en Ciencias Sociales Universidad de Buenos Aires, Becaria CONICET Tipo II.
} 
la proclamación de la igualdad de derechos a nivel formal y las desigualdades económicas y sociales que conllevó el modelo económico implantado (DONZELOT, 2007, p. 34).

En el período que retomamos, a partir de la Primera Guerra mundial, hubo cambios a nivel económico por la suspensión en el envío de productos manufacturados y combustibles y por la baja de los precios de los productos agropecuarios que el país vendía. Desde estos años comenzaron tentativas para instaurar un modelo de sustitución de importaciones con la creación, por ejemplo, de la Dirección de Industrias. Sin embargo, hubo una relativa continuidad del esquema espacial consolidado a principios de siglo y funcional a la incorporación del país al mercado mundial. La Primera Guerra Mundial también tuvo como uno de sus efectos una inversión en la corriente inmigratoria ya que hubo alrededor de 92.000 retornos (CHIOZZA, 1971, p. 29), aunque recomenzó lograda la paz y alcanzó entre 1921 y 1930 los más altos niveles, debido a que hubo un saldo de 878.000 inmigrantes efectivamente radicados. En términos políticos, se produjo una transición de un régimen oligárquico hacia uno democrático. Ésta fue paulatina y se inició en 1912 con la sanción de la Ley Sáenz Peña del voto masculino, secreto y obligatorio. Las elecciones de 1916 llevaron a Hipólito Irigoyen a la presidencia, quien había representado a sectores populares y a hijos de inmigrantes que buscaban integrarse en el país (ROMERO, 1996, p. 127).

Para este período la ciudad de Buenos Aires había sufrido una gran transformación, en términos culturales y sociales, como efecto del proceso de integración de los contingentes inmigratorios. Hubo diversidad de preocupaciones en torno a quienes llegaban al ser considerados principales culpables del aumento de la tasa de criminalidad y alcoholismo en la ciudad. Hacia la década del 1920 apareció un notable interés por la cuestión de los niños desde discursos provenientes de médicos, criminólogos, abogados y funcionarios públicos. En especial, por aquellos que circulaban sin destino por la calle ya que fueron identificados como futuros delincuentes. La intervención sobre la niñez en estratos pobres y de sectores inmigrantes fue vista como una manera de prevenir conductas criminales. Desde 1919 apareció en Argentina legislación específica en torno a la niñez. El primer ejemplo tendiente a la regulación y control legal de la niñez fue la sanción de la Ley de Patronato $N^{o} 19.903$ sancionada en 1919 que se ocupó de la niñez abandonada y reguló la cuestión de la 
patria potestad. Más adelante, se sancionó la ley N 4.664 en 1937 que estableció la creación de tribunales específicos para niños.

Dentro de los intereses que aparecieron por controlar la niñez peligrosa, surgió uno particular por la niñez de "mala vida", es decir, aquella que fue vinculada a una zona vaporosa entre la delincuencia y la locura y que estuvo ligada a situaciones sociales y económicas de pobreza. La "mala vida" incluyó la niñez que se encontraba cercana a actividades peligrosas, como la prostitución o que tenía estigmas de degeneración o necesidades materiales. También incluyó a la niñez considerada peligrosa que fue estudiada desde un punto de vista endocrinológico como aquella que, por el funcionamiento anormal o desequilibrio de su sistema endócrino u hormonal, tenía "tendencias al delito".

En esta oportunidad, nuestro objetivo es el abordaje que se realizó de la categoría de "mala vida" desde las historias clínicas producidas en el Depósito de Contraventores de la Policía de la ciudad de Buenos Aires y la noción de la peligrosidad infantil desde el punto de vista de la endocrinología. Estos discursos aparecieron en la Revista de Criminología, Psiquiatría y Medicina Legal que retomamos como fuente documental dentro del cuadro histórico analizado. En lo que sigue, presentaremos brevemente el rol del positivismo como corriente en la que se ubicó su discurso y las teorías sobre la degeneración. Luego, nos referimos brevemente a sanción de la Ley de Patronato en 1919 como una forma de intentar controlar el fenómeno de la niñez peligrosa y abandonada y al papel de los jueces que atendían en los casos de los niños, siendo que en este período todavía no había tribunales específicos. Además, el papel del Depósito de Contraventores de la policía de la ciudad de Buenos Aires, desde el que se realizaron historias clínicas a niños que eran remitidas a los jueces que conocían en sus procesos. En este sentido, nos referiremos a las historias clínicas de Carmen y Emilia "la turkita", niñas que ejercían la prostitución. Estas historias fueron producidas en el Depósito y la oficina técnica de la Penitenciaría Nacional. Luego, nos dedicaremos a describir aspectos de la construcción de la niñez peligrosa desde el punto de vista de la endocrinología y biotipología como corriente que planteaba un "avance" respecto de los estudios de César Lombroso. En particular, nos detendremos en las referencias a la niñez peligrosa antes de nacer a partir de los efectos de ciertos estímulos sobre el sistema endócrino de la madre (alcoholismo, agotamiento por trabajos manuales) y en el niño peligroso por el anormal funcionamiento de sus glándulas sexuales, que lo podían llevar en el futuro a la criminalidad. 
El rol del positivismo y teorías sobre la degeneración. Presentación Revista de Criminología, Psiquiatría, Medicina Legal y Ciencias Afines (1914 - 1934)

Como establecimos más arriba, los discursos que tendremos en cuenta para estudiar la "mala vida", tanto aquellos del Depósito de Contraventores de la Policía de Buenos Aires, como los provenientes de estudios médicos de la corriente endocrinológica, fueron publicados en Revista de Criminología, Psiquiatría Medicina Legal y Ciencias Afines. Esta revista se encuadró dentro de la tradición positivista que puede ser definida como una corriente de pensamiento filosófico que a la vez conformó un programa científico y una estrategia de política social. Fue una epistemología y una ontología que colocó, siguiendo a Susana Murillo, a la ciencia en el lugar de verdad. Además, fue entendido en el sentido de una manifestación más avanzada del progreso que posibilitaría la perfectibilidad tanto moral como social del hombre (MURILLO, 2011, p. 87).

El prestigio y valor de la ciencia como una herramienta para el gobierno de los Estados artículo tres ejes: En primer lugar, las instituciones específicas (hospitales, prisiones, escuelas, comisarías). En segundo lugar, un sistema teórico que se basó en el positivismo, desde el que se articuló la locura con el delito y se los diferenció de la normalidad. Las publicaciones periódicas como las que analizamos sirvieron para la difusión de conceptos teóricos y de los registros de prácticas médicas, penitenciarias y policiales. En tercer lugar, una capa de profesionales que se incorporó a puestos públicos vinculados a la educación, criminalidad y salud (MURILLO, 2011, p. 86).

La preocupación por la niñez de "mala vida" estuvo influida en Buenos Aires por los estudios provenientes del positivismo criminológico de César Lombroso y, hacia la década del 1920, con los de la endocrinología a partir de la introducción de Nicolás Pende en Argentina.

\footnotetext{
Según Lombroso el niño criminal surgía del mantenimiento de sus instintos primitivos, como consecuencia de un deficiente desarrollo y maduración de sus estructuras nerviosas. Este somaticismo a ultranza tuvo como origen y fondo la teoría de la degeneración, porque para la psiquiatría positivista el niño criminal era un niño degenerado sometido a influencias hereditarias diversas que hacían de él un individuo que permaneciendo en un "estado regresivo", sería considerado por algunos como un verdadero enfermo. (HUERTAS, 1987, p. 137).
}

Las teorías sobre la degeneración, cuyo abordaje excede este trabajo, ofrecieron argumentos de tipo científicos sobre los que se construyeron metáforas en las que se 
plantearon paralelismos entre la degeneración, como fenómeno biológico ligado a la muerte y la enfermedad, y, la decadencia social.

El español Ricardo Campos Marín ha estudiado diversas razones del éxito de estas teorías, así como de su gran difusión en países europeos: En primer lugar, éstas resumieron miedos y angustias desde fines del siglo XVIII y principios del siglo XIX en Europa cuando el optimismo librecambista comenzó a chocar con crisis económicas y amenazas revolucionarias (MARÍN; PÉREZ; HUERTAS, 2000, p. 11), específicamente en Francia, donde recibió una primera sistematización teórica por el alienista Gustave Morel. Dos años después de la aparición del libro de Darwin El Origen de las Especies, Morel dio a conocer su teoría de la degeneración en 1857. En su obra alertaba sobre el aumento de delitos contra la propiedad, enfermedades mentales y suicidios entre la población. Su tesis fundamental fue que los trastornos psíquicos constituían expresión de la constitución anormal del organismo de los individuos. En segundo lugar, estas teorías respondieron a la inquietud de la medicina positivista por encontrar las causas de la alienación mental. Se podrían establecer mecanismos para prevenir la misma si se podían conocer su etiología y diagnosticar aquellos casos de alienación "en potencia." Desde una concepción somaticista estricta remitía la enfermedad a un sustrato físico - anormal constitución corporal - y permitía explicar la clínica proteiforme y asistemática de la enfermedad mental a través de la tendencia al desequilibrio que tenía el terreno orgánico donde surgía (MARIN, PÉREZ; HUERTAS 2000, p. 13).

Más adelante, hacia la década de 1920 en Italia, se postuló que para la detección de la otredad peligrosa se debía conocer escrupulosamente la estructura íntima del cuerpo y del alma:

Ubicando al cuerpo dentro de una escala evolutiva desde la que se podía comenzar la mejora racial. Su especificidad radicó en que se inclinó por conocer los rasgos morales ocultos más que los estigmas físicos que podían ser advertidos por la antropometría planteada por Lombroso. De esta manera se identificaban potenciales criminales y perturbadores de una utópica normalidad social, entre ellos a los niños, incluyendo a los que estaban por nacer. (MIRANDA, 2009, p. 157).

El "mal" o peligro que debía ser repelido por el Estado estuvo asociado al alcoholismo, la prostitución y la homosexualidad.

Antes de seguir, tendremos en consideración que la Revista de Criminología, Psiquiatría Medicina Legal y Ciencias Afines, fue inaugurada en 1914 y dirigida por 
Helvio Fernández, discípulo de José Ingenieros en el Instituto de Criminología de la Penitenciaría Nacional. En esta publicación escribieron diversos operadores del sistema judicial, penitenciario, médico y policial. Es por ello que configura un reservorio para observar ciertos fenómenos relativos al abordaje de la marginalidad social. Además, fue la continuación de la revista Archivos de Psiquiatría, Criminología, Medicina Legal y Ciencias Afines dirigida por José Ingenieros entre 1902 y 1913, que hemos estudiado en otra oportunidad (DOVIO, 2010, p. 10).

En esta publicación se abordaron diversidad de temas, entre los que se encontraron la cuestión de la criminalidad, enfermedades mentales y físicas, problemáticas sociales como el alcoholismo, entre otros. Se publicaron historias clínicas, fallos judiciales y pericias psiquiátricas realizadas en la prisión a detenidos y pacientes de hospitales. También aparecieron trabajos académicos realizados tanto por profesores de la Universidad de Buenos Aires, como por profesores extranjeros de Perú, Brasil, España e Italia. Por otra parte, surgieron una serie de trabajos provenientes de dependencias públicas, como hospitales, prisiones y escuelas en los que se establecían detalles acerca de su funcionamiento a partir de estadísticas, número de internados, por ejemplo, y causas de las internaciones.

En cuanto al diseño de la revista entre 1924 y 1934 podemos establecer que contó con 4 secciones: 1) sección de artículos originales, seguida de otra de 2) Documentos Judiciales, donde se publicaban extractos o fallos judiciales completos y vistas fiscales. Luego, una sección de 3) Variedades, en los que aparecieron textos cortos relativos a temas específicos. Como por ejemplo "La enseñanza de la higiene sexual en las escuelas", otros relativos al alcoholismo, el derecho penal y cuestiones sociales. Por último, cada número de la revista terminaba con una sección de 4) Análisis de Libros y Revistas.

Escribieron asiduamente en la etapa de la revista 1914 - 1919 los articulistas Arana Zelis y Antonio Lucero (Médicos de los Tribunales de Buenos Aires) Eusebio Gómez (policía y adscripto al Instituto de Criminología), Víctor Delfino (médico), Dr. Jorge Frías (Presidente de la Excma. Cámara de Apelaciones en lo Criminal de Buenos Aires), Doctor Jorge Coll (Agente Fiscal en los Tribunales de Buenos Aires), Doctor Carlos de Arenaza (Médico de la policía de Buenos Aires) Dr. José M. Paz Anchorena (Abogado y adscripto al Instituto de Criminología de Buenos Aires), Doctor Tomás Jofré (Profesor en la Universidad de Buenos Aires y la Plata), Ernesto E. Rossi Buenos 
Aires (Secretario de la Penitenciaría Nacional) y el Juez Dr. Lucas Luna Olmos, entre otros.

\section{Niñez delincuente y peligrosa en Buenos Aires}

Uno de los principales problemas que en 1923 detectó Carlos de Arenaza, médico en el Depósito de Contraventores de la Policía de la ciudad de Buenos Aires, fue el aumento de la criminalidad infantil en la ciudad; tanto respecto del número de atentados como de su gravedad. Estableció que la misma tenía diversidad de causas sociales relacionadas con la "mala vida". Dentro de ellas se encontraron la prostitución, el alcoholismo y la miseria. "Anémicos y hambrientos, lanzados a la calzada, explotados como animales de carga por patrones desconsiderados cuando no entregados a la prostitución por sus propias madres." (ARENAZA, 1923a, p. 41). A ello se sumaba los padres "ignorantes y torpes" que los explotaban mediante la venta de diarios y la mendicidad. Éstos eran los terrenos que "cultivaban" la tuberculosis, la delincuencia, la degeneración y el alcoholismo.

Según Carlos de Arenaza (1931, p. 676) sobre 2000 niños que había observado en el Depósito de Contraventores, había hallado antecedentes de alcoholismo entre los progenitores de 769 de ellos o sea el 38,35\%; en 174 casos al alcoholismo estaba ligado a la neurosis y en 77 en consorcio con la tuberculosis. El alcoholismo fue considerado un vicio típico de la clase trabajadora urbana que buscaba en el alcohol una forma de evadirse ante el mundo hostil que lo rodeaba. De esta forma, los trabajadores aparecían como responsables de su propia situación. El alcoholismo fue considerado una de las causas más importantes de alienación mental y degeneración (HUERTAS, 1987, p. 90).

El $17,5 \%$ de los menores estudiados procedían de padres neuropáticos, comprendiendo en esta denominación general desde la alienación hasta el histerismo [...] El hogar normal es la excepción en la familia del niño delincuente, sólo lo encontré en el $18 \%$ de los casos clasificados; la regla es la acumulación de taras hereditarias y ambientales. (ARENAZA, 1931, p. 676-677).

La delincuencia contra la propiedad, según señalaron el médico Vicente Sierra y el penitenciario José María Anchorena “[...] era la delincuencia del momento y en sus filas se reclutaban la mayor cantidad de menores que allí se iniciaban en su carrera del delito". (ANCHORENA, 1918, p. 112). Los niños y sus pequeños ilegalismos de bienes, arrebatos o ínfimos disturbios, fueron incluidos dentro de lo que se llamó “[...] 
delincuencia flotante sobre la ciudad." (SIERRA, 1917, p. 47). Ésta, que aumentaba con las deficiencias de la legislación penal, dejaba en libertad, según la policía (con sobreseimientos provisorios y condenas insignificantes) a la mayor parte de los delincuentes "profesionales".

Si el ladrón es el parásito, como dice Sergi, de la criminalidad, éste tiene a su vez otros parásitos, menores en su mayoría, que escapan en el $95 \%$ de los casos de toda acción judicial eficiente. Son estos llamados en la terminología profesional, campanas, bomberos, entregadores, etc. (SIERRA, 1917, p. 48).

La cuestión de los niños fue ligada a la prevención de la delincuencia. Se consideró que la misma podría lograrse mediante la fortificación de los cuerpos de los niños atravesados por taras hereditarias, educación insuficiente, peligros del mal ambiente. El estudio íntegro del niño en lo físico, moral y ambiental debía ser el criterio de los criminólogos, según Anchorena, no para castigar a los niños, sino para evitar la repetición: educando, refrenando los impulsos o inculcándole principios y sentido de moralidad. El delito del niño fue concebido como "[...] un signo revelador, el grito de alarma, que nos indica al niño en peligro de caer, al niño que hay que auxiliar, al que hay que instruir y educar." (ANCHORENA, 1918, p. 110).

En 1919 se sancionó en Argentina la Ley de Patronato por el médico Luis Agote. Con ella se buscó darle una solución al problema del encierro de niños que circulaban en la calle en situación de "peligro moral y material" a través de la derivación de los mismos a establecimientos de asistencia con trabajo "regenerativo" (GUTIERREZ, 2009, p. 233). Fue innovadora en Latinoamérica y casi contemporánea de las legislaciones europeas y estadounidenses. Abarcó situaciones en la que los niños se encontraban abandonados o cometían actos antisociales que no llegaban a constituir un delito.

Mediante la misma se redefinieron y ampliaron las facultades del Estado para suspender o quitar la patria potestad a los padres (STAGNO, 2010, p. 133). Los jueces podían realizar lo anterior cuando los padres hubieran sido condenados por delitos graves o por delitos contra sus hijos, o si habían sufrido graves condenas que demostraban que se trataba de "delincuentes profesionales o peligrosos". También, cuando sin haber sido condenados comprometían la salud, la moralidad o la seguridad de sus hijos por ebriedad consuetudinaria, inconducta notoria o escandalosa, malos tratos, negligencia culpable y, en general, cuando los menores se encontraban moral o materialmente abandonados. Esta ley implicó que el tratamiento judicial y penal fuera 
específico para los niños. Antes de la sanción de la misma, los niños de 10 años eran juzgados y procesados como adultos y los menores de 10 años eran considerados inimputables (ZAPIOLA, 2007, p. 305). La sentencia dependía del grado de discernimiento que el juez estableciera en los niños y se les aplicaban las mismas penas que a los adultos pero reducidas en un tercio y no podían ser condenados a la pena de muerte.

Luis Agote presentó su proyecto de Ley sobre Patronato en cuatro oportunidades entre 1910 y 1919. Una de las razones que permitieron su sanción fue el recrudecimiento de los conflictos sociales desde 1917 y los violentos eventos a partir de la "Semana trágica" en los que murieron miles de trabajadores. Los acontecimientos, según María Carolina Zapiola, parecían confirmar las proyecciones más oscuras de las elites acerca de la amenaza política que significaban los niños callejeros y abandonados que circulaban por los espacios urbanos (ZAPIOLA, 2010, p. 122). Una ley del tipo que presentó Luis Agote parecía responder a este miedo dado que estipulaba el encierro de estos niños en establecimientos especializados destinados a su regeneración "moral".

\section{Depósito de Contraventores de la Policía}

En el período analizado los niños que eran detenidos por motivo de un delito o contravención en la ciudad de Buenos Aires podían ser enviados al Cuadro V de la Policía, Depósito de Contraventores, Cárcel de encausados, Colonia Marcos Paz o Cárcel de Mujeres. Todos ellos, salvo la Colonia Marcos Paz, carecían de un lugar y tratamiento especial para niños y según Sierra allí se enteraban de "[...] todas las prácticas de onanismo y pederastia." (SIERRA, 1917, p. 75). El Depósito de Contraventores, que funcionó dentro de la Policía de Buenos Aires no había sido originalmente planeado para alojar niños. Entre 1902 y 1911 había funcionado allí el Servicio de Observación de Alienados donde fueron detenidos individuos que presentaran "signos de enajenación mental", entre ellos "lunfardos" (llamados así quienes cometían pequeños robos en espacios urbanos), vagabundos e invertidos sexuales (DOVIO, 2010, p. 40).

José María Paz Anchorena describió el estado de detención de los niños en el Depósito de Contraventores que había visitado el 17 de agosto de 1918. Había encontrado 50 niños detenidos, la mayor cantidad por abandono de sus padres, eran "conocidos" por la policía y habían reincidido. 
Aquella no puede ser peor escuela de vicio, en salas de espacio reducido donde se alojan los menores, y a pesar de que la dirección se ocupa en clasificarlos por grupos de acuerdo con sus antecedentes y edades, hemos podido ver facciones que indicaban niños abandonados, junto a un trigueño de mirada oblicua, provocadora. A todo esto agreguemos el peor estado higiénico, en salas donde no hay camas, donde la promiscuidad y holganza los convida a la pederastia, y donde las infecciones son frecuentes. (ANCHORENA, 1918, p. 581).

Los niños que llegaban al Depósito habían sido detenidos por un delito, como robo o hurto en la mayor parte de los casos, o por contravenciones, principalmente por la venta de diarios o ejercicio de la prostitución. Una contravención constituyó una falta a un Código Contravencional. La diferencia entre la contravención y el delito, desde el punto de vista criminológico, no fue cualitativa, sino cuantitativa. Es decir, los delitos se consideraron desde un punto de vista amplio como actos antisociales que se castigaban por las leyes. Eran por ello, antijurídicos y diversos, porque podían quebrar lo establecido por un Código Penal o por normas municipales, reglamentos, etc. La particularidad de las contravenciones fue que se presentaron como hechos contingentes y variables, accidentales, de carácter secundario que variaban según la "moralidad" del medio social. Para Vicente Sierra la situación moral, era la que determinaba, no sólo la situación material sino la mayor o menor producción de contravenciones: "A tanta moralidad, tantos contraventores." (SIERRA, 1917, p. 53).

Carlos de Arenaza fue el principal encargado de realizar las historias clínicas sobre los niños alojados en el Depósito de Contraventores junto a otros médicos. Trabajó 18 años en esta dependencia, y, en una ocasión, confeccionó 70 historias clínicas a niños del Depósito para la Comisión Asesora de Asilos y Hospital Regional, a pedido de su director el doctor Domingo Cabred, para trasladarlos la Colonia Escuela Olivera. De ellos 10 fueron diagnosticados como retardados mentales, 12 como degenerados mentales, 2 epilépticos, 4 afectados de tuberculosis y 2 tuberculosos y neuropáticos.

La mayoría de los niños detenidos en el Depósito tenían menos de 13 años de edad. "El 70\% tiene entre 6 y 11 años: seres a los que hay que vestir y alimentar, incapaces de producir." (ARENAZA, 1923b, p. 500). Según Arenaza una de las razones por las que no había niños mayores era porque cuando cumplían entre 11 o 12 años eran retirados por los padres para que trabajaran, es decir, para utilizarlos como "factores de producción". Muchos de los niños padecían de hambre al llegar al Depósito 
Las observaciones recogidas en la Alcaidía de menores resultan concluyentes: nuestros niños callejeros delincuentes o abandonados ingresan hambrientos y la balanza nos da la clave en no pocos casos de la verdadera causa de la delincuencia infantil. (ARENAZA, 1923a, p. 49).

De allí que el tratamiento que los "curaba" era un régimen alimenticio adecuado. A ellos se sumaban, según Arenaza, la administración de purgantes o de gramos de boruro.

Por el Depósito de Contraventores pasaron gran cantidad de niños en el período analizado. Arenaza destacó la importancia que tenía realizar en ellos un informe médico psicológico prolongado ya que el mismo serviría de insumo principal al juez que entendiera en el proceso judicial. La observación del niño constante durante el día y el sueño, debía durar entre tres y cuatro meses. Se establecía que si era menos tiempo el niño tendría la posibilidad de "disimular" su situación. Según Arenaza "El sistema de Binet Simon ${ }^{1}$ puede contribuir a formar el concepto sobre la instrucción y la intelectualidad, pero el conocimiento del carácter, de los sentimientos, la moral e inclinaciones, etc., sólo se obtiene por observación personal." (ARENAZA, 1923a, p. $58)$.

A lo largo de este tiempo el médico debía averiguar acerca de sus antecedentes familiares y ámbito social en el que se desenvolvía, aptitud para el trabajo, carácter, de sus amigos y relaciones, moralidad y situación económica. Arenaza destacó que en muchos de los casos observados tuvo un importante papel la cuestión de la afectividad.

\begin{abstract}
En los cientos de niños que me ha sido estudiar, encontré muchos insensibles, indiferentes, cuando no reacios al afecto, a la caricia o al halago. ¿Es que son locos morales? No ¿Es que faltan en absoluto los sentimientos afectivos? No. Es que muchos de ellos no las conocieron de padres idiotizados por el vicio, ni de sus madres muertas al darles vida, de ahí que se retiren sorprendidos y desconfiados ante la palabra cálida, ante la caricia paternal, ante el afecto exteriorizado en un ademán, es que ellos no conocieron sino el golpe brutal, la imprecación obscena. (ARENAZA, 1923a, p. 51).
\end{abstract}

El médico peruano Altman Smythe citó una historia clínica de Carlos de Arenaza sobre el caso de Carlos que había ingresado a la Alcaldía de la policía de Buenos Aires por una falsa denuncia de su madrastra. A través del mismo se refirió al maltrato familiar:

\footnotetext{
${ }^{1}$ Test destinado a la predicción del rendimiento escolar elaborado por el francés Alfred Binet con colaboración de Theodore Simon en 1903.
} 
Este niño que con su trabajo costeaba el sostenimiento del hogar paterno, no tenía derecho de concurrir a él sino a la hora de la cena...tan pronto terminaba ésta debía retirarse a un almacén próximo donde la madrastra le había alquilado una habitación, un altillo oscuro y frío...no podía permanecer en la casa que sostenía con su trabajo porque la madre postiza decía que era un peligro para el propio hijo; la verdad era otra: ese niño ejemplar, hacía sombra al hijo de la segunda unión. (SMYTHE, 1934, p. 516).

Respecto de su detención puntualizó “ ¡Cuantos muchachos son apresados por la torpe policía debido a una denuncia que muchas veces significa pesados tormentos sufridos por estos infelices niños!”. El comportamiento del niño había sido ejemplar mientras había estado detenido en la Alcaidía:

[...] en su estadía se hizo cargo de la enseñanza y cuidado de un grupo de chiquillos de 5 y 6 años, los cuidaba, les enseñaba a leer. Intervine con el juez y le busque colocación y lo envié a la estancia del Sr. Guerrero. Dos meses después me escribía enviando un cajón de frutas para sus antiguos protegidos. (SMYTHE, 1934, p. 516).

Los datos que recolectaba el médico para su informe en el Depósito policial eran destinados al juez que entendía en el proceso judicial de los niños. En estos años eran los mismos jueces que para adultos debido a que todavía no existían todavía Tribunales específicos. Aunque ellos fueron uno de los núcleos de la Ley de Patronato, desde la misma no se estableció un fuero especial para niños, sino que se confirió facultades especiales a los Tribunales de Apelación en lo Criminal y Correccional de la Nación, Capital Federal y territorios nacionales para poder designar a uno o más jueces que entendieran exclusivamente en aquellos casos que involucraban a niños. En 1937 se sancionó la ley 4.664 a partir de la cual se hizo posible la creación del primer Tribunal para niños en Argentina, “[...] la instauración de un fuero especial y el nombramiento de un juez de menores especialmente dedicado a las causas que incluían a niños y adolescentes." (STAGNO, 2011, p. 352).

Se consideró que los jueces que entendían en estos casos, aunque no pertenecieran a un Tribunal para menores, debían cumplir la función de un "tutor a cargo del menor". En este sentido, era necesario que conocieran la materialidad del hecho y la situación de la familia, género y condiciones de existencia, lugares que frecuentaban, la manera de ser y el carácter de los que ejercían influencia sobre él. En Revista de Criminología se debatió el rol del juez antes de la sanción de la ley 4.664, a partir del modelo judicial norteamericano e inglés. El principio en común de estos 
modelos con Argentina estuvo dado por la consideración de la tutela estatal como forma de permitir a los jueces intervenir en casos de peligro moral o material.

Telma Reca, médica argentina que se dedicó en la década del 1940 a la psiquiatría infantil, fue una de las difusoras del sistema juvenil estadounidense. En su tesis doctoral presentada en 1932 se había dedicado al análisis del caso de la Corte Juvenil de Chicago que según ella había inaugurado una nueva etapa en materia jurídica sobre menores (STAGNO, 2011, p. 354). En Revista de Criminología, Reca definió a los tribunales infantiles como "[...] el órgano oficial del Estado destinado a la consideración de los delitos infantiles cuya raíz se encontraba en el grupo familiar o ambiente social del interesado." (RECA, 1932, p. 159).

Carlos de Arenaza, por su parte, se encargó de difundir el modelo inglés de justicia infantil en la revista que estudiamos. En Inglaterra se había promulgado en 1908 la Children`s Act que legislaba sobre la internación de menores y la vigilancia de instituciones donde eran destinados, la tenencia de los padres, prohibición de venta de tabaco y alcohol a menores de 16 años y reformatorios. Ella dio lugar a la creación de las Juvenils Courts destinadas a niños menores de 16 años. También se dedicó a describir como modelo a seguir la "Remand Home", así llamadas en Inglaterra a los lugares para la detención provisional de niños. Arenaza expresó: “¿Qué falta nos haría en nuestra tierra imitar un poco a los ingleses!; en nuestra alcaidía de menores pasan actualmente 1.200 niños, algunos permanecen en ella hasta dos años." (ARENAZA, 1929, p. 300).

\section{Prostitución infantil}

En 1919 Carlos de Arenaza publicó ocho historias clínicas realizadas en la Oficina de estudios médicos legales de la Penitenciaría Nacional y en el Depósito de Contraventores de la Policía en los que aparecieron aspectos de la "mala vida" en relación al ejercicio de la prostitución en niñas. Siguiendo a María Luisa Múgica, la prostitución fue

[...] visualizada como un problema privado y público. En cuanto problema privado, apareció directamente ligado a la moral individual aunque, sin duda, excedía esta esfera, y, era fundamentalmente registrado como una cuestión pública que podía afectar a todos. Por otra parte, la prostitución apareció en ciertos ámbitos en términos de una sexualidad ilegítima que se opuso a una legítima privilegiada por la elite dirigente. Ésta última se centraba en la intimidad y el individualismo, tradicionalmente llamada "moral victoriana" que no era de ocultamiento, sino de proliferación de discursos y saberes sobre la sexualidad. (MUGICA, 2009, p. 344). 
Los niños en situaciones familiares y sociales adversas aparecían expulsados de sus hogares para realizar trabajos de supervivencia, como fue el caso del ejercicio de la prostitución. Carlos de Arenaza estableció “[...] la futura prostituta abandona desde temprano el hogar de sus progenitores, que no tiene para ella ningún atractivo." (ARENAZA, 1919, p. 11). Según Ciafardo algunos niños se iniciaban tempranamente en la vida sexual como parte de la cotidianeidad que descubrían en las calles y de las que tarde o temprano aprendían a sacar algún rédito económico (CIAFARDO, 1992, p. 20).

El presidente de la Cruz Roja, el Doctor Raúl Ortega Belgrano estableció que para evitar este despertar sexual precoz se debía cambiar la disposición de las habitaciones en las casas para que los hijos no durmieran en el mismo cuarto que los padres y otros factores como la supresión del folletín o cine obsceno y el contacto con niños de otro sexo desde edades tempranas a partir de la educación mixta. También estableció propuestas relativas a la capacidad educadora de los médicos en las capas sociales más desfavorecidas, se debían

\footnotetext{
Mejorar las condiciones físicas y morales de la clase menesterosa. Esto último se podría conseguir repartiendo cartillas explicativas de los peligros sexuales, y por medio de la acción constante de la enfermera visitadora. La Cruz Roja de la juventud debe desempeñar importantísimo papel, cultivando en el varón sentimiento de responsabilidad, por su conducta ante el sexo femenino. Como dice René Sando, la prostitución sólo disminuye donde la moralidad del hombre se eleva. (BELGRANO, 1927, p. 312).
}

En las historias clínicas que retomamos en esta ocasión se realizó una averiguación de los antecedentes de las niñas, dónde estaban sus padres, de qué manera vivían o de qué habían fallecido. También se elaboró un identikit respecto de las relaciones socio - laborales de cada niña, con quiénes se vinculaba y si pasaba tiempo en la calle.

Carlos de Arenaza se refirió a ocho casos de niñas que describió de la siguiente manera:

Carmen S. de 14 años de edad, española, ocupación: vagabunda, detenida por hurto. Características personales: prostituta con estigmas de degeneración. Padre: tuberculoso y madre inmoral.

-Angélica M. 15 años, argentina, ocupación: sirviente, prostituta con tendencia al suicidio y degenerada. Hija natural de madre concubina.

-Emilia A, 10 años, argentina, ocupación: vendedora de periódicos, prostituta con fisiología pobre: padre falleció de tuberculosis y madre tuberculosa.

-Esperanza M. 12 años, argentina vendedora de periódicos, prostituta clínica, degradada, padre falleció y madre histérica inmoral. 
-Elisa D. 13 años, argentina: vaga, prostituta, mendiga con estigmas de degeneración con padre alcohólico.

-Blanca E.C. 14 años paraguaya, sirvienta, detenida por hurto, padre fallecido tuberculoso, madre inmoral, prostitución inadaptable con estigmas físicos.

-Carmen P. 13 años argentina, vendedora de periódicos, prostituta y ratera, se desconoce el paradero de los padres.

-Ramona P. 13 años de edad, argentina, vendedora de periódicos, prostituta, tampoco se tiene antecedentes de los padres. (ARENAZA, 1919, p. 10).

Nos detendremos en dos casos debido a que en uno de ellos la prostitución apareció criminalizada y en el otro explicada como parte de una situación de pobreza. Por una parte, el caso de Carmen S., en el que se vinculó la prostitución a la degeneración moral, la delincuencia y relaciones con otros "malvivientes". Por otra parte, el caso de Emilia "la turkita" en el que la prostitución es analizada como una forma de la niña de ayudar en su hogar por la situación económica desfavorable.

Carmen S. era una niña de 13 años de edad de nacionalidad española que había sido procesada por delito de hurto. Su estudio clínico fue realizado por el médico de la policía Carlos de Arenaza en compañía del doctor Alfredo E. Oliverio (médico de la Penitenciaría Nacional) a pedido del juez doctor Lascano.

Su historia comenzó con la descripción de sus padres, como antesala de la descripción de la vida que llevaba:

\begin{abstract}
Esta procede (refiriéndose a Carmen) de un hogar irregular, fué (sic) su padre un alcoholista crónico [...] durante muchos años fué (sic) portero del Patronato de la Infancia, donde se le toleraba no obstante su vicio, en mérito de su miseria, a lo numeroso de su familia [...] Madre fecunda, pero de dudosa moralidad, no supo o no pudo encaminar rectamente su prole; de los once hijos que aún viven, la mayor parte de las mujeres lo hacen en concubinato. (ARENAZA, 1919, p. 12).
\end{abstract}

En cuanto a las relaciones que mantuvo Carmen con otros individuos que pertenecían a esta "mala vida" los médicos destacan el de otros dos niños, Raúl y Ramón, que eran sus souteners y prestaban ayuda como "campanas" de Carmen.

Se cuidó siempre de no andar sola; así es que se hacía acompañar, primeramente, por un simpático pilluelo, de 11 años de edad, llamado Raúl (pero como la madre de éste no lo dejaba andar de noche), de ahí vino la presentación de Ramón de 14 años. En cuanto al modo de operar de Carmen y Ramón se estableció que la primera [...] elige las horas en que parte del personal de los comercios dejan el negocio durante la hora del almuerzo, pero de preferencia en las horas de la tarde o de la noche cuando van a cerrar los negocios; entonces, mientras Ramón "hace guardia" en la puerta de la calle o en la esquina próxima, ella penetra al interior donde satisface los apetitos sexuales de jóvenes degradados o de viejos decrépitos [...]. (ARENAZA, 1919, p. 27). 
La actividad de Carmen aparece descripta a modo de un delito. Por ese entonces, el ejercicio de la prostitución en la ciudad de Buenos Aires no estaba penado, sino que su ejercicio estaba reglamentado (entre 1875 y 1934 funcionaron reglamentos municipales). Los médicos participaron activamente de este modelo de control violento sobre la sexualidad de las mujeres. Es decir, muchas de las cuestiones del sistema de prostitución reglamentada, presuponían una mirada y auxilio médico. Así como, indicaciones precisas sobre todo en lo relativo acerca de cómo prevenir enfermedades venéreas, por ejemplo la tuberculosis, la sífilis en las casas de prostitución, cómo vigilar a las mujeres y realizarles los exámenes periódicos. Su presencia y prácticas eran fundamentales, así como la del brazo policial, en la implementación de la reglamentación.

En la historia clínica de Carmen se acumularon aspectos que se ligaron entre sí en la descripción de una "mala vida". A un cuadro familiar de marginalidad social se sumó la realización de pequeños robos y el ejercicio de la prostitución. Las necesidades del cuerpo, como el hambre, se ligaron a falencias de tipo moral. De esta forma se criminalizaron conductas consideradas "irregularidades morales".

En el caso de Emilia "la turkita" se estableció que

\begin{abstract}
No siempre la prostitución infantil tiene por fin entretener vagos, realizar orgías o aumentar el peculio o los vicios de padres desnaturalizados. En la prostitución infantil también vemos verdaderas heroínas, [...] únicos sostenes de un hogar derrumbado por la miseria y la enfermedad, La menor Emilia, conocida con el apodo de "la Turquita" [...] se la ve con frecuencia por nuestras calles centrales; delgaducha, de rasgos agraciados, de cabello rubio sucio, vistiendo una pollerita corta de colores vivos y zapatos de alto tacón Luis $\mathrm{XV}$, vende periódicos, jabones, peines, o implora la caridad pública; tales son sus ocupaciones visibles; la real es recorrer los escritorios y casas de comercio y masturbar a individuos degradados que le retribuyen con centavos sus favores. (ARENAZA, 1919, p. 29-30).
\end{abstract}

Esa criatura, mantenía con su prostitución a una madre agonizante, cuidaba y alimentaba a sus hermanitos menores y aun tenía energías para rebelarse de una persecución policial que no le "permitía trabajar". En este caso la niña que ejercía la prostitución era considerada una víctima de la situación familiar y social en la que vivía. "Esto formó parte del ideario socialmente compartido respecto de que el ejercicio de la prostitución era la vía más rápida y fácil de una mujer para salir de la pobreza". (CARREÑO, 2005, p. 108).

Carlos de Arenaza consideró que la solución para frenar el ejercicio de la prostitución en las niñas era que se les prohibiera la venta de periódicos o el desempeño 
de otras ocupaciones en la vía pública. Se consideró que era en la escuela donde debían formarse las futuras madres y que debía privarse de la patria potestad a padres "inmorales". También se consideró que era de urgencia la creación de un "verdadero patronato" de la infancia, que fue creado efectivamente en 1931.

\section{Niños peligrosos y la endocrinología}

La importancia de la descripción externa del cuerpo, en estas historias clínicas, puede ser relacionada con el avance de los estudios endocrinológicos y eugenésicos en Argentina en la década de 1920 a partir de los cuales se agregó a ellos el estudio de las hormonas y el sistema nervioso. Uno de sus principales representantes fue el médico italiano Nicolás Pende. Él fue un importante soporte intelectual y científico del fascismo, régimen político instaurado en 1922 en Italia, y también “[...] supo difundir la biotipología en países latinoamericanos, donde su influencia fue particularmente intensa desde 1930, sobre todo en Brasil y Argentina." (VALLEJO, 2007, p. 30). Desde la biotipología se impulsó el conocimiento del "interior" del hombre delincuente, marcando una ruptura con las aproximaciones lombrosianas que suponían que el estudio fenotípico de los sujetos permitiría adelantar sus posibles actitudes delictivas. Entre ellas estuvo la importancia del análisis del papel de las hormonas y el sistema endócrino.

La endocrinología sirvió como una herramienta para la búsqueda de las causas de la peligrosidad y delincuencia en general y del niño en particular. Se consideró que la base biológica del estado peligroso se encontraba en el desequilibrio endócrino. Es decir, en la influencia que el sistema endócrino tenía en la constitución del temperamento normal y en las variedades patológicas del mismo. Las glándulas de secreción interna influían en la constitución del individuo, actuaban sobre su fisiologismo, vida humoral, temperamento y vida intelectual. "Pende ha dicho de la fórmula endócrina individual depende la personalidad psíquica de todo sujeto." (SMYTHE, 1934, p. 420). El anormal funcionamiento del aparato endócrino del niño podía hacerle adquirir peligrosidad.

Desde esta perspectiva, al acto delictuoso resultaba posible explicarlo por el funcionamiento anormal del sistema endócrino. Las secreciones internas producían una serie de acciones fisiológicas como psicológicas y sus desequilibrios servían para advertir un estado peligroso. Las dos glándulas de secreción interna que mayor 
influencia tenían en el sujeto eran: tiroides (excitaban la vida emotiva y aceleraban las reacciones motoras y psíquicas) y las suprarrenales (glándulas dinámicas por excelencia). Las hormonas, por otro lado, influían en la organización y morfología del cuerpo y en la vida psíquica. Las sustancias que segregaban las glándulas endócrinas eran "mensajeros químicos” que complementaban la acción del sistema nervioso.

Por otra parte, factores externos provenientes de la naturaleza tenían efectos sobre el sistema endócrino y hormonal:

\begin{abstract}
Se perciben más delitos en primavera por el hiperfuncionamiento de las glándulas de secreción interna [...] los factores climáticos y atmosféricos tienen influencia en la criminalidad porque repercuten sobre el sistema endócrino. Los factores climáticos como el sol, la humedad, el mar o la presión atmosférica estimulan o retardan el funcionamiento de la tiroides y suprarrenales. (SMYTHE, 1934, p. 421).
\end{abstract}

Las glándulas también influían en el estado emocional y carácter de las púberes y embarazadas. Las distintas fases del carácter en la vida del sujeto y distinta intelectualidad y sentimientos entre sexos dependían de la fisiología de las glándulas sexuales. Una serie de trastornos genitales actuaban poderosamente en la "génesis" de la criminalidad.

El niño podía ser peligroso ya antes de nacer porque

[...] la peligrosidad del menor puede ser adquirida en el vientre materno, también en el momento de la concepción [...] cualquier intoxicación, cualquier trastorno de las glándulas endócrinas, en fin, cualquier desequilibrio orgánico que se produzca en la madre, puede repercutir en el menor, dando lugar a una transformación física y psíquica tal, que lo convierta en un ser orgánicamente peligroso. (SMYTHE, 1934, p. 416).

Dos de los factores que podían alterar las glándulas endócrinas y afectar en la futura peligrosidad del menor fueron el alcohol y el agotamiento en las mujeres trabajadoras. Respecto del primero se estableció que el alcohol al ser ingerido

[...] recorre todo el organismo materno y el fetal [...] produciendo profundas alteraciones y degeneraciones en el ser que se plasma e inoculándole, puede decirse, peligrosidad, que más tarde o más temprano hará su temible aparición en el niño o en el adulto. (SMYTHE, 1934, p. 416).

Se consideró que el alcohol siempre producía perturbaciones diversas que alcanzaban a los hijos porque las "[...] células sexuales sufren la acción nociva del tóxico, determinando la blastofloxia de Forel, es decir, la enfermedad de la célula germinativa." (SMYTHE, 1934, p. 408). 
En cuanto al agotamiento de las mujeres se colocó el ejemplo de las mujeres costureras que trabajaban 18 horas por día sin descanso apropiado y alimentándose deficientemente, lo que tenía efectos en su vientre y en el futuro niño.

El niño que nacía de padres considerados degenerados, fuera por el alcohol, una enfermedad venérea o mental, estaba en "peligro de adquirir una personalidad antisocial objetiva". Para impedir estas situaciones se proponía la salida eugenésica de evitar esos nacimientos, esterilizando a "degenerados", “[...] que llevan en latencia la causa de un probable estado peligroso posible de manifestarse en el niño que ha visto la luz en tales condiciones orgánicas." (SMYTHE, 1934, p. 451).

En el niño, los trastornos endocrinológicos podían ser más frecuentes, dado que se encontraba en pleno desarrollo. Esto implicaba que las causas de desequilibrios del sistema endócrino fueran mayores que en los adultos y éstas estaban particularmente gobernadas por la edad. Además, las hormonas también actuaban como elementos de control del sistema nervioso, es decir, que el equilibrio endócrino conducía a un equilibrio en las reacciones objetivas y subjetivas. Los niños, debido al estado de su sistema nervioso, tenían una menor capacidad de control y discernimiento moral que los adultos.

Específicamente, el irregular funcionamiento de la glándula pineal producía un anormal desarrollo de las características sexuales secundarias y precocidad sexual, impulsándolo a actos contra el pudor o delitos de esta naturaleza. Se consideró que este funcionamiento irregular de las glándulas de secreción interna podía, con el tiempo, llegar a producir tendencias al delito cuando el niño fuera adulto. De modo que había que prevenir estas primeras manifestaciones de actos contra el "pudor".

\section{Reflexión final}

La cuestión de la niñez de "mala vida" y, más adelante, la peligrosidad endocrinológica de los niños configuró una preocupación desde el campo del discurso médico, policial y penitenciario en el período analizado en la Revista de Criminología.

Surgieron distintas propuestas destinadas a procurar controlar la niñez peligrosa. En este sentido, la sanción de la Ley de Patronato en 1919 marcó un cambio en materia de legislación sobre niñez porque el Estado se arrogó mayores facultades para la intervención respecto de la niñez abandonada y delincuente. Aunque fue presentada como una ley de educación y de introducción de criterios científicos, implicó un 
aumento en el ejercicio de la violencia contra el niño al postular su institucionalización generalizada no sólo por delincuencia o abandono, sino por "mala conducta", que podemos entender como referido a llevar una "mala vida".

En el abordaje de la niñez de "mala vida" tuvo importancia el Depósito de Contraventores de la Policía de la ciudad de Buenos Aires. Aunque no fue una dependencia específicamente destinada a los niños, se produjeron diversas historias clínicas sobre los niños allí alojados. Carlos de Arenaza fue el principal encargado de realizarlas y ocupó un relevante lugar en los estudios sobre la marginalidad social infantil en Argentina.

Los casos de las historias clínicas del Depósito de Contraventores sobre la cuestión de la prostitución, permiten poder establecer cómo era construida en cada caso la etiología de la "mala vida". Ésta resultaba de una combinación entre factores provenientes del ambiente, sobre todo la carencia de alimentos, trabajo y vestimenta que volvían necesario que el niño trabajara, se prostituyera o robara para sobrevivir. Además, se agregó el estudio de las causas "orgánicas" de la "mala vida". Ellas estuvieron configuradas por la "degeneración", concepto amplio que permitió ubicar una serie de enfermedades como el alcoholismo y la epilepsia que se consideraba que, a lo largo de las generaciones, debilitaban al cuerpo y lo volvían propenso a la locura o el delito. De allí la importancia de los antecedentes familiares, enfermedades de los padres y modo de vida.

Si bien se estudió la morfología del niño, retomando los estudios de César Lombroso, es necesario tener en cuenta que en este período comenzó a tener relevancia el estudio de las hormonas y el sistema endócrino a partir de los estudios biotipológicos de Nicolás Pende. Desde los mismos se consideraba que se podría determinar cuál era la peligrosidad del niño. Tuvieron en cuenta el aspecto ambiental (ejemplo la influencia del clima, la presión atmosférica en el funcionamiento hormonal) y los aspectos morales y familiares. Es decir, aunque se prestó especial atención al estudio hormonal y endócrino, pretendió ser a la vez un estudio integral que abarcaba los aspectos morfológicos, psíquicos y sociales. A lo que le agregaba los aspectos químicos y efectos del sistema endócrino sobre los comportamientos y las emociones.

En el caso de la construcción de la peligrosidad de los niños apareció la relevancia de la cuestión de la sexualidad. El inicio sexual temprano y ejercicio de la prostitución, así como los abusos sexuales fueron vinculados a las malas condiciones de 
vida de las familias. Por ejemplo, a que los niños tuvieran que dormir en el mismo cuarto que los padres. La sexualidad también cobró relevancia porque la peligrosidad de los niños fue asociada a los desequilibrios hormonales sexuales ya sea por un desenvolvimiento precoz, por la dificultad para el control de las emociones que venían dados, sobre todo, por las hormonas relativas a la sexualidad. 


\title{
Children and "low life." Child prostitution, criminalization and endocrinology in Buenos Aires between 1914 and 1934
}

\begin{abstract}
The aim of this work is to analyze the construction of the notion of the "low life" in relation to children in Buenos Aires between 1914 y 1934. By "low life" we understand those behaviors related to delinquency and alcoholism. In particular, certain marginal activities that were linked to children as prostitution and small thefts in urban spaces. To do this, we will consider the production of medical records from the Deposit of Offenders that functioned in the Buenos Aires Police. Also, we will study the notion of child dangerousness from the point of view of endocrinology and biotypology, studies initiated by Nicholas Pende, of great influence in Argentina. The discourses we will study appeared in the Review of Criminology, Psychiatry and Legal Medicine that was representative of de criminological positivism in Argentina.
\end{abstract}

Keywords: Children; "Low life"; Prostitution; Endocrinology.

\section{REFERENCIAS}

ANCHORENA, José María. Prevención de la delincuencia de los menores. Revista de Criminología, Psiquiatría y Medicina Legal, Año IV, Buenos Aires: Talleres Gráficos de la Penitenciaría Nacional, 1918.

ARENAZA, Carlos de. Prostitución infantil. Revista de Criminología, Psiquiatría y Medicina Legal, Buenos Aires: Talleres Gráficos de la Penitenciaría Nacional, 1919.

ARENAZA, Carlos de. Menores delincuentes, clasificación y estudio médico psicológico. Revista de Criminología, Psiquiatría y Medicina Legal, Buenos Aires: Talleres Gráficos de la Penitenciaría Nacional, 1923a.

ARENAZA, Carlos de. El asilo policial. Revista de Criminología, Psiquiatría y Medicina Legal, Buenos Aires: Talleres Gráficos de la Penitenciaría Nacional, 1923b.

ARENAZA, Carlos de. Establecimiento para la detención provisoria de menores. Remand Home. Revista de Criminología, Psiquiatría y Medicina Legal, Buenos Aires: Talleres Gráficos de la Penitenciaría Nacional, 1929. 
ARENAZA, Carlos de. La readaptación social del menor delincuente. Revista de Criminología, Psiquiatría y Medicina Legal, Buenos Aires: Talleres Gráficos de la Penitenciaría Nacional, 1931.

ARMUS, Diego. La ciudad impura. Salud, tuberculosis y cultura en Buenos Aires, 1870 - 1950. Buenos Aires: Editorial Edhasa, 2007

BELGRANO, Raúl Ortega. Las verdaderas causas del aborto provocado en la mujer soltera. Revista de Criminología, Psiquiatría y Medicina Legal, Buenos Aires: Talleres Gráficos de la Penitenciaría Nacional, 1927.

CARREÑO, Karina Liliana. Noches alegres, muchachas tristes. La prostitución legal en Tandil (1870 - 1910). Tandil: Municipio de Tandil, Dirección de Cultura, 2005.

CHIOZZA, Elena. La población argentina estancada. In: la Clase Media en el Poder. Buenos Aires: Centro Editor América Latina, 1971.

CIAFARDO, Eduardo. Los niños en la ciudad de Buenos Aires (1890- 1910). Buenos Aires: Centro Editor América Latina, 1992.

DONZELOT, Jacques. La Policía de las Familias. Buenos Aires: Ediciones Nueva Visión, 2005.

DONZELOT, Jacques. La invención de lo social. Ensayo sobre la declinación de las pasiones políticas. Buenos Aires: Editorial Nueva Visión, 2007.

DOVIO, Mariana. La "mala vida" en la revista Archivos de Psiquiatría, Criminología, Medicina Legal y Ciencias Afines. Tesis de Maestría, Inédita, Buenos Aires: FLACSO, 2010.

GUTIERREZ, Talía. Violeta Estado, minoridad y delito urbano - rural (1933-1943). In: MIRANDA, Marisa; SIERRA, Álvaro Girón (Org.). Cuerpo, Biopolítica y Control Social América Latina y Europa en los siglos XIX y XX. Buenos Aires: Editorial Siglo XXI, 2009.

HUERTAS, Rafael. Locura y degeneración. Madrid: Editorial Consejo Superior de Investigaciones Científicas, 1987.

MIRANDA, Marisa. Eugenesia en Argentina: aportes para una comprensión epositemológica. In: MIRANDA, Marisa; SIERRA, Álvaro Girón (Org.). Cuerpo, Biopolítica y control social. Buenos Aires: Editorial Siglo XXI, 2009.

MARÍN, Ricardo Campos; PÉREZ, José Martínez; HUERTAS, Rafael. Los ilegales de la naturaleza. Medicina y Degeneracionismo en la España de la Restauración (1876 - 1923). Madrid: Editorial Consejo Superior de Investigaciones Científicas, 2000.

MÚGICA, María Luisa. Entre el reglamentarismo y el Código de Faltas. Una mirada histórica sobre la relación entre prostitución, policía y poder político en Rosario. In: SOZZO, Máximo (Coord.). Historia de la cuestión criminal en la Argentina. Buenos Aires: Editorial del Puerto, 2009. 
MURILLO, La ciencia aplicada a políticas sanitarias en Argentina y su relación con la escuela de Medicina de la Universidad de Buenos Aires (1869-1905) Tesis de Maestría en Gestión Política de la Ciencia y la Tecnología. Buenos Aires: Centro Cultural de la Cooperación, 2011.

RECA, Telma. Estudio social del niño delincuente. Revista de Criminología, Psiquiatría y Medicina Legal. Buenos Aires: Talleres Gráficos de la Penitenciaría Nacional, 1932.

ROMERO, José Luis. Breve Historia de la Argentina. Buenos Aires: Editorial Fondo de Cultura Económica, 1996.

SMYTHE, Julio Altman. El problema del menor en estado peligroso. Revista de Criminología, Psiquiatría y Medicina Legal. Buenos Aires: Talleres Gráficos de la Penitenciaría Nacional, 1934.

STAGNO, Leandro. Infancia, juventud y delincuencia a través de una práctica judicial. Las primeras actuaciones del Tribunal de Menores número 1 (Buenos Aires 19371942). In: LIONETTI, Lucía; MIGUEZ, Daniel. (Org.). Las infancias en la historia argentina, Intersecciones entre prácticas, discursos e instituciones. Rosario: Prohistoria Ediciones, 2010.

STAGNO, Leandro. Los Tribunales de Menores en Argentina, Antecedentes internacionales e iniciativas nacionales (1933- 1943). In: COSSE, Isabella; LLOBET Valeria; VILLALTA, Carla; ZAPIOLA, María Carolina (Org.). Infancias: políticas y saberes en Argentina y Brasil siglos XIX y XX. Buenos Aires: Editorial Teseo, 2011.

SIERRA, Vicente. La minoridad que delinque en la ciudad de Buenos Aires. In: Revista de Criminología, Psiquiatría y Medicina Legal. Año IV, Buenos Aires: Talleres Gráficos de la Penitenciaría Nacional, 1917.

VALLEJO, Gustavo. Cuerpo y representación: la imagen del hombre en la eugenesia latina. In: VALLEJO, Gustavo; MIRANDA; Marisa (Comps.). Políticas del cuerpo. Estrategias modernas de normalización del individuo y la sociedad. Buenos Aires: Editorial Siglo XXI, 2007.

ZAPIOLA, María Carolina. Niños en las calles: imágenes literarias y representaciones oficiales en la Argentina del centenario. In: GAYOL, Sandra; MADERO; Marta (Org.). Formas de Historia cultural. Buenos Aires: Editorial Prometeo y Universidad Nacional General Sarmiento, 2007.

ZAPIOLA, María Carolina. La ley de Patronato de Menores de 1919. ¿Una bisagra histórica. In: LIONETTI, Lucía; MIGUEZ, Daniel (Comps.). Las infancias en la historia argentina, Intersecciones entre prácticas, discursos e instituciones. Rosario: Prohistoria Ediciones, 2010. 